\title{
PROJETO CUCA: ESTRATÉGIA DE CONSERVAÇÃO JUNTO A COMUNIDADE DE ENTORNO AO PARQUE ESTADUAL DA CANTAREIRA-SÃO PAULO-BRASIL
}

\author{
Fernando Descio ${ }^{1}$, Aleksandra Furtado Mendes ${ }^{2}$, Aparecida Descio ${ }^{3}$, Fausto Assumpção ${ }^{4}$, \\ Carina Zorzeti ${ }^{5}$, Diego Hernandes R. Laranja ${ }^{6}$ \\ ${ }^{1}$ Pesquisador Cientifico Instituto Florestal \\ ${ }^{2}$ Coordenadora Programa de Uso Público e Educação Ambiental \\ ${ }^{3}$ Participante do Grupo de Educação Ambiental Fundação Florestal \\ ${ }^{4,5,6}$ Equipe de Uso Público e Educação Ambiental
}

\section{RESUMO}

O Parque Estadual da Cantareira (PEC) é uma Unidade de Conservação de Proteção Integral criada através do decreto no 41.626/63, atualmente gerenciado pela Fundação Florestal órgão vinculado a Secretaria de Estado do Meio Ambiente. Possui 7.916,52 hectares e abrange parte dos municípios de São Paulo, Mairiporã, Caieiras e Guarulhos é um dos últimos remanescentes de Mata Atlântica, rico em mananciais e que abriga diversas espécies de fauna e flora ameaçadas de extinção.

Por estar inserido em uma das maiores metrópoles urbanas do mundo sofre com as pressões provenientes de uma sociedade em expansão como: a ocupação urbana desordenada, despejos irregulares de lixo, caça predatória, incêndios e invasões de moradores do entorno para as mais diversas finalidades, que colocam em risco a integridade da Unidade prejudicando assim nosso objetivo maior que é o de conservar os recursos naturais oferecidos pelo PEC para as atuais e futuras gerações. A fim de minimizar a degradação o PEC elaborou o Projeto Cuca, uma estratégia de Conservação que vem agindo na comunidade de seu entorno através de parcerias com as associações de bairro e diversos atores da comunidade desenvolvendo atividades de sensibilização e mobilização ambiental e assim a conseqüente conservação desta área.

Palavras Chaves: Educação Ambiental, comunidade, Unidade de Conservação

\section{INTRODUÇÃO}

O Parque Estadual da Cantareira (PEC) é uma Unidade de Conservação de proteção integral criada através do decreto no 41.626/63, atualmente gerenciado pela Fundação Florestal, órgão vinculado a Secretaria de Estado do Meio Ambiente. Possui 7.916,52 hectares e abrange parte dos municípios de São Paulo, Caieiras, Mairiporã e Guarulhos, é um dos últimos remanescentes de Mata Atlântica, rico em mananciais e que abriga diversas espécies de fauna e flora ameaçadas de extinção(FF, 2009). É dividido em quatro Núcleos de visitação: Pedra Grande, Águas Claras, Engordador e Cabuçu, sendo o Núcleo Pedra Grande o primeiro a ser inaugurado em 1989.

A preocupação em proporcionar à população lazer, recreação e educação ambiental foi citada no Plano de Manejo em 1976 (IF), no intuito de formar nos visitantes uma consciência conservacionista e uma reflexão sobre seu comportamento em relação ao meio ambiente.

Este primeiro Plano de Manejo auxiliou o Parque a organizar um Programa de Uso Público melhor estruturado tornando-o capaz de receber visitação do público geral e de escolares, com dias e 
horários pré determinados, e a principal atividade a ser oferecida pela equipeera o "Estudo de Meio" ou como chamado naquela oportunidade de "Programa de Educação Ambiental: Trilha de Interpretação da Natureza" nas trilhas da Bica e Pedra Grande, localizadas no Núcleo Pedra Grande.

Com o crescimento dos atendimentos ao longo dos anos, ocorreu claramente uma maior divulgação

do

Parque e dos seus serviços prestados à comunidade com atividades internas de Educação Ambiental.

De acordo com Fernando Descio, (pesquisador cientifico que trabalhava no PEC desde aquela época e hoje exerce a função de Gestor do Parque)observou-se a necessidade de expandir o Programa de Uso Público atuando diretamente nas comunidades do entorno imediato, visto que estas comunidades de ocupação desordenada conflitavam com os interesses de conservação e preservação do Parque. Por serem desprovidasde equipamentos de lazer e cultura, se utilizavam das dependências fechadas ao Uso Público para suas práticas recreativas, além disto, havia captação de água irregular, acumulo de lixo pelo uso da área para prática de esportes e de cultos evangélicos, e que, por sua vez, resultavam no corte do sub-bosque abrindo diversas clareiras, trilhas secundárias e incêndios florestais isolados.

Pimentel, 2008, observa que os problemas que podem ser mantidos entre as UCs de Proteção Integral e as comunidades do entorno do Parque podem indicar uma fragilidade das ações administrativas frente à sociedade. Ainda diz que as atividades de manejo dentro de um Parque, não estão apenas relacionadas às questões ecológicas, mas também dependem da relação mantida com as comunidades que "usam" o local.

Reforça-se esta idéia num trecho do guia realizado pela Secretaria de Estado de Meio Ambiente, de 1991 apud Vitiello, 2003 que cita:

“(...) há que destacar a presença da população que vive no entorno e pode ser exercer um importante papel na fiscalização e conservação das unidades. Essa é uma das razões pela qual as UC's e Produção apresentam-se como espaços facilitadores e enriquecedores para $o$ desenvolvimento de diversos programas de Educação Ambiental"

Baseado nisso, notou-se a importância de entender a realidade local e como esta população enxergava a inserção de uma área de conservação em um ambiente que sempre foi visto, popularmente falando, como o "quintal" de suas casas. Levando em consideração que seu uso efetivo era apenas para recreação e lazer, ignorando a importância histórica e ecológica local. Sendo assim, a necessidade de inserção de um projeto de Educação Ambiental no entorno com estratégias capazes de criar um sentimento de pertencimento e de tornar a comunidade parceira de conservação do PEC, foi se tornando cada vez mais evidente.

\section{${ }^{1}$ CONTEXTUALIZAÇ̃̃o HISTÓRICA}

A região da Serra da Cantareira sempre foi conhecida por abrigar água abundante e boa para consumo. Até o século XIX abrigava diversas fazendas com culturas de café, chá e cana-de-açúcar, cuja implantação acarretou a derrubada de grande parte da cobertura vegetal nativa.

Ainda no século XIX a cidade passou a se desenvolver cada vez mais sendo necessários equipamentos coletivos urbanos como, o abastecimento de água, rede de esgoto, fornecimento de energia e todos os demais de maior magnitude que pudessem compor o desenvolvimento da

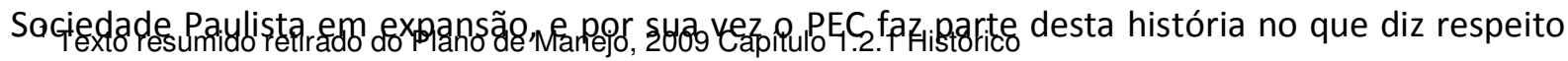


ao abastecimento de água de São Paulo, que é conhecido atualmente como "Antigo Sistema Cantareira".

Até meados de 1850 o abastecimento de água de São Paulo era realizado através da captação das águas das Represas do Engordador, Cassununga e Cachoeira, porém em 1893 com a explosão da população paulista, a Superintendência de Obras Públicas instituiu a R.A.E. (Repartição de Águas e Esgoto), com a missão de custear e executar o abastecimento de água e rede de esgoto da Capital, já naquela época se entendia perfeitamente a importância da floresta e então o governo comprou diversas propriedades para a proteção da mata que abrigava os mananciais, reformou estes antigos reservatórios e construiu novos que foram chamados de Represas da Cuca, Depósito, Divisa, Manino, Ytaguassu, Olaria, Guaraú e Engordador, ampliando o abastecimento de água capaz de suprir as necessidades da Capital.

A partir de 1973 este Sistema foi sendo desativado aos poucos, pois havia uma crescente população em São Paulo, a qual este Sistema passou a não ser mais tão eficiente. Parte da infraestrutura do sistema de abastecimento de água do Antigo Sistema Cantareira foi destruída ao longo do tempo, no entanto, estão praticamente preservadas aquelas que se encontram no perímetro do Parque Estadual da Cantareira, mais precisamente na região Oeste,já o sistema de distribuição, situado na área urbana, foi destruído com duas exceções: a Caixa da Consolação, e a da Liberdade que ainda estão em uso.

Pivelli, 2006 diz que a convivência com o mundo natural tem sido cada vez menor em vista do crescente processo de urbanização. No Brasil, por exemplo, $80 \%$ da população vivem nas cidades, longe das áreas naturais (WILSON, 2003 apud PIVELLI, 2006), o que demonstra esta crescente migração do interior para as cidades.

Por ainda existirem estes tanques e represas, a área Oeste do PEC abriga grande parte da história do abastecimento de água de São Paulo que hoje é considerado patrimônio tombado pelo CONDEPHAT.Em 2009 com os estudos do Plano de Manejo, estaregião é considerada segundo o novo zoneamento do PEC de zona de Recuperação e Histórico-Cultural.

\section{O NASCIMENTO DO PROJETO}

O Parque está localizado na região norte da cidade de São Paulo, formando parte do Cinturão Verde do Estado de São Paulo, por este motivo sofre comumente com os impactos de uma sociedade em constante crescimento. De acordo com o censo populacional realizado pelo IBGE (Instituto Brasileiro de Geografia e Estatística) em 1963, ano de criação do Parque Estadual da Cantareira, o Estado de São Paulo tinha 12.974.699 habitantes. Ainda de acordo com o Instituto, este número cresceu para 41.262.199 em 2010, é possível notar que a população triplicou em menos de 50 anos e houve a eminente necessidade de ampliação de diversos serviços.

Desta forma em 1999, iniciou-se o processo de solicitação de área do Parque para servir depassagem das linhas de transmissão (LT) de energia chamada: Anhanguera- Guarulhos, a serem instaladas pela empresa CTEEP (Companhia de Transmissão de Energia Elétrica Paulista), estas LT's estão presentes atualmente na porção norte do Parque, em toda a sua extensão,e foi neste momento que a Equipe de Uso Público, atuante na época, observoua oportunidade de vincular um projeto de educação ambiental com as comunidades do entorno, como condicionante à licença de operação das linhas de transmissão, é possível avistá-las de alguns pontos do parque, inclusive no mirante da Pedra Grande.

A área escolhida para a atuação do Projeto foi a região Oeste ao Parque, que como já dito anteriormente abriga grande parte da História do abastecimento de água de São Paulo, esta 
região é administrada pela Subprefeitura Brasilândia/Freguesia do Ó, que segundo dados demográficos de 2010 obtidos através do site institucional da Prefeitura, possui uma população de 407.245 pessoas e abrange os bairros: Jd. Vitória Régia, Jd. Damasceno, Jd Paraná, Jd. Vista Alegre e Jd. Recanto. Esta é uma área de extrema fragilidade social, de acordo com Vitiello, 2003 a face Sudoeste do PEC é onde se encontram bairros extremamente populosos do município de São Paulo com população de baixa renda. Segundo o mapa de inclusão e exclusão social, realizado pela PUC em 2002, inserido em seu trabalho, a nota de exclusão atribuída ao distrito de Brasilândia é de $-81,1$, levando em consideração que, índices inferiores de -75 demonstram uma condição de extrema exclusão social. E tais bairros estão inseridos na zona de amortecimento, beirando os limites do PEC, e por este motivo geram uma grande pressão antrópica sobre o Parque, não podemos nos esquecer que a Unidade está inserida na área urbana sendo impossível transformála em uma ilha de preservação, assumindo que assim como diz Fritjof Capra, 1996

"Quanto mais estudamos os principais problemas de nossa época, mais somos levados a perceber que eles não podem ser entendidos isoladamente. São problemas sistêmicos, o que significa que estão interligados e são interdependentes"

Sendo então impossível pensar em conservação sem que pensemos nas pessoas como agentes de mudanças e de transformação.

Este projeto em parceria com a CTEEP recebeu o nome de "Projeto Cuca: Conhecer para Preservar", pois na região existe a Represa da Cuca e a Estrada da Vista Alegre, que foi apelidada pela equipe de fiscalização posteriormente de Trilha da Cuca, dando assim origem ao nome do Projeto.

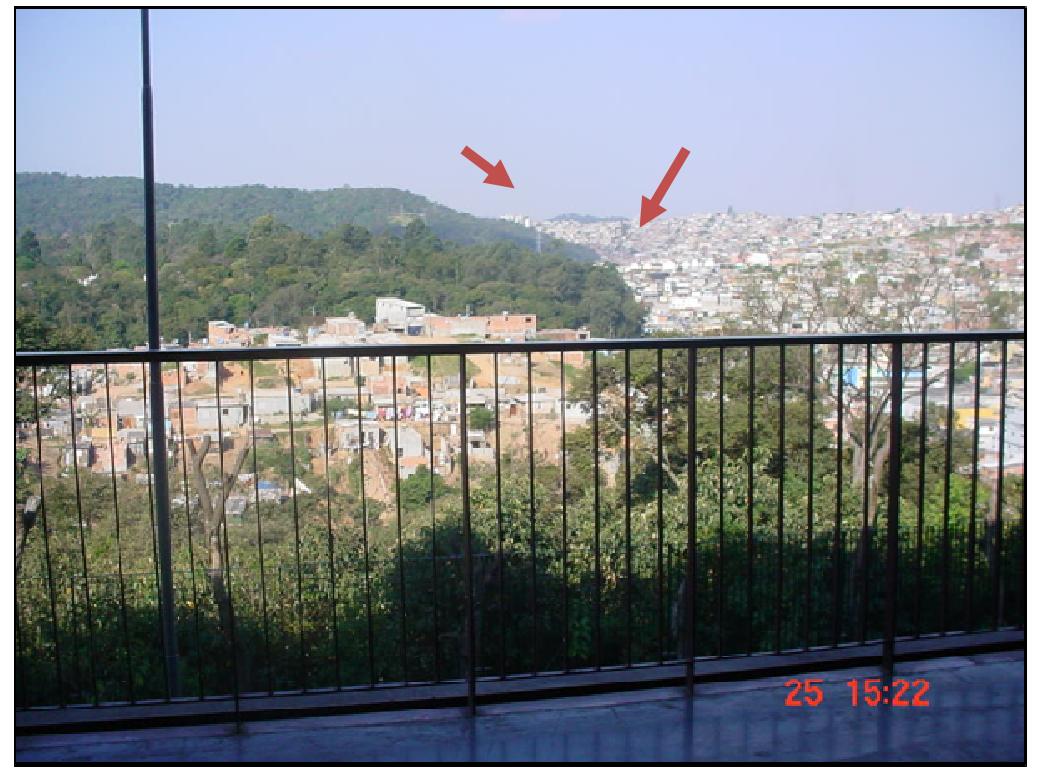

Fig. 01: Vista do Bairro Jardim Paraná. Nota-se os limites do PEC e as Linhas de Transmissão de Energia Elétrica 


\section{METODOLOGIA}

A aprovaçãoda Licença de Operação ocorreu em 2005, dando inicio a contratação da equipe de educação Ambiental e a aquisição de materiais para a execução do Projeto. A principio a equipe era formada por 1 Coordenador e 6 Monitores Ambientais e os materiais adquiridos foram: equipamento de informática, 1 projetor de mídia, 1 câmera digital, material de papelaria diversos para oficinas, uniformes e um veículo.

Esta equipe desenvolveu um cronograma de ações para a atuação.A primeira ação realizada foi a visita nas comunidades para conhecer e escolher as Associações potenciais,principalmente que já desenvolviam atividades de sensibilização e mobilização relacionados à conservação do meio ambiente, a fim de estabelecer parcerias e apresentar a proposta do Projeto.

Em janeiro de 2006 ocorreu à primeira reunião comunitária chamada de "1으 Encontro de Ação Ambiental", que teve como objetivo definir as ações a serem realizadas.

Estas foram divididas da seguinte forma:

- Palestras nas escolas: os temas escolhidos eram: Mata Atlântica, Importância do Parque Estadual da Cantareira, História do abastecimento de Água e Poluição;

- Mutirão de limpeza na Estrada da Cuca: uma vez por mês a equipe de educação ambiental, mais os membros da comunidade e a equipe de limpeza da Sub Prefeitura removiam o lixo acumulado nos antigos tanques;

- Preserve a Cuca: intervenção educativa na região em que ocorriam os cultos evangélicos,as regiões foram mapeadas pela equipe sendo determinadas como prioritárias as áreas da Avenida Santa Inês e a região de Taipas. Os monitores contavam com a participação da Policia Militar Ambiental, pois com o impacto causado pelos evangélicos (abertura de clareiras e trilhas secundárias principalmente) a região que é de extrema vulnerabilidade social, passou também a ser freqüentada por dependentes químicos. A ação consistia em uma explanação geral sobre a área, a importância do Parque e terminava com um convite para a visita as áreas de Uso Público.

- Atendimento às escolas do entorno: no inicio de cada semestre era encaminhada para as Diretorias Regionais de Educação uma Carta convidando todas as escolas de seu domínio administrativo para participarem das atividades de Educação Ambiental, especificas para escolas, desenvolvidas pelo Parque, cada visita durava em média 2 horas e 30 minutos, sendo atendidos até 50 estudantes, no período da manhã das 8:30h às 11:30 ou no período da tarde das 13:30 às 16:30, de acordo com a disponibilidade da escola.

- Atividade Cultural: eram definidas datas, de acordo com o Calendário Ecológico padrão, para a realização de atividades diferenciadas com o público visitante do Parque e com a comunidade de entorno nas escolas e associações de bairro. As atividades mais comumente realizadas eram: teatro, exposição e oficinas de reciclagem.

O contrato da Equipe de Monitoria era renovado a cada 12 meses, a partir de 2010 o contrato passou a ser de 3 (três) anos. 


\section{RESULTADOS E DISCUSSÃO}

Para que as Linhas de Transmissão pudessem operar eram entregues a ONG Guatambu, (responsável pela contratação terceirizada da equipe e de entregar os relatórios a empresa CTEEP que por sua vez uni todos os documentos a sua licença de operação para repassá-los a Secretaria de Estado e Meio Ambiente e a CETESB - Companhia de Tecnologia de Saneamento Ambiental), um Relatório de Execução de Atividades, estes sofreram várias mudanças, ora eram entregues mensalmente ora a cada trimestre e em formatos diferentes, fato este que dificultou o levantamento da quantidade de cada ação realizada no período de 2006 a 2009, pois em muitos relatórios constavam apenas o relato, sem dados de quantidade.

Os dados apresentados nestes relatórios consideravam os resultados pontuais das ações e mediam o seu "sucesso" de acordo, principalmente, com a quantidade de participantes presentes em cada atividade, a avaliação era realizada de acordo com as observações e sensações que a equipe tinha em relação ao trabalho realizado.

De acordo com estes relatórios no período de Janeiro/2006a Março/ 2007 (este foi também o período do primeiro contrato)diversas ações de mobilização na comunidade ocorreram tais como, reuniões comunitárias, atividades culturais em datas comemorativas com a presença de diversos órgãos estatais e da comunidade, visitas e vistorias a Trilha da Cuca que geraram um levantamento de perfil do "visitante" do local, em que se constatou que sua presença estava ligada intrinsecamente ao uso da área para prática de lazer e esportes, e que apesar deste visitante saber da existência dos núcleos de visitação, preferia o local por ser mais próximo a sua casa. Além do atendimento das escolas de entorno comumente atendidas no Programa de Uso Público do PEC, as associações de bairro e ONGs locais também realizavam agendamentos, e estas atividades eram diferenciadas, os assuntos tratados eram trazidos por participantes destas instituições. Era comum também a presença dos monitores nas escolas para realização de palestras em que os temas mais abordados eram Mata Atlântica, Poluição e Água.O projeto se iniciou com a participação de 69 líderes comunitários, de 26 associações atingindo 15 bairros.

O segundo contrato foi renovado e teve atuação no período de Novembro/2007 a Novembro/2008, é possível notar que se passou 8 (oito) meses até a renovação, uma grande lacuna nos trabalhos junto a Comunidade, que ocasionou a perca de relação com diversas associações. Um novo coordenador assumiu o Projeto e diversas atividades foram reformuladas. Os trabalhos de visita as escolas da comunidade ficaram restritos a uma escola apenas (CEU Paraná), presente no Jd. Paraná e as atividades realizadas foram oficina de reciclagem, teatro e um show com banda de Reggae Ecológico, que de acordo com os relatórios foi muito bem aceito, principalmente com os jovens. A ação "Preserve a Cuca" também ocorreu, e estavam relatadas em quase todos os relatórios, portanto acreditamos que houve uma maior intensidade em sua execução, sempre atreladas a participação da Policia Militar Ambiental e GCM Ambiental, os horários das ações eram predominantemente de madrugada, momento em que os líderes religiosos se encontravam para a "vigília". A equipe notou a diminuição da presença destes membros nas áreas comumente invadidas para estas práticas. Houve também mutirões de limpeza da Trilha da Cuca, porém não foi possível saber quantos.

Novamente o contrato foi encerrado e a renovação ocorreu em fevereiro de 2009. Mais uma vez houve a troca do coordenador, que por sua vez definiu novas estratégias e ações. A atuação da equipe ocorreu em outra escola (EE Dílson Funaro), presente no Jd. Flamingo. As atividades realizadas foram: Concurso Cultural de Desenho que definiu um personagem para o projeto. Os alunos mostraram-se muito empolgados com a atividade e a equipe avaliou quase 400 desenhos 
de estudantes de 8 a 12 anos, houve também a premiação deste concurso, e o vencedor como prêmio de incentivo ganhou camiseta, boné e uma mochila personalizada. A Policia Militar Ambiental participou realizando palestra e exposição de objetos provenientes do tráfico. Após o concurso a equipe desenvolveu um Teatro que contava a história do personagem e a importância da conservação do Parque, fato também que atraiu diversos estudantes. Foi realizada uma palestra com os estudantes de idades entre 13 e 15 anos sobre a história da ocupação da Mata Atlântica e sua degradação, que mobilizou os estudantes para a realização de um plantio em uma área interna cedida pela escola, foi uma atividade que simbolizou a participação da escola na proteção e conservação da Mata Atlântica. As ações de mutirão de limpeza e Preserve a Cuca, também ocorreram, uma vez ao mês cada uma.

Ao longo destes três anos relatados,foi comum encontrarmos observações, tanto da equipe , quanto dos líderes comunitários principalmente sobre a diminuição de lixo na trilha da Cuca e na área dos tanques e também sobre a diminuição da presença dos grupos evangélicos e abertura de novas clareiras, isto nos demonstra que de certa forma, apesar de inexistência de indicadores de avaliação, o Projeto alcançava a população que auxiliava na conservação do PEC.

As fotos abaixo representam um pouco do registro fotográfico das equipes que participaram do Projeto.
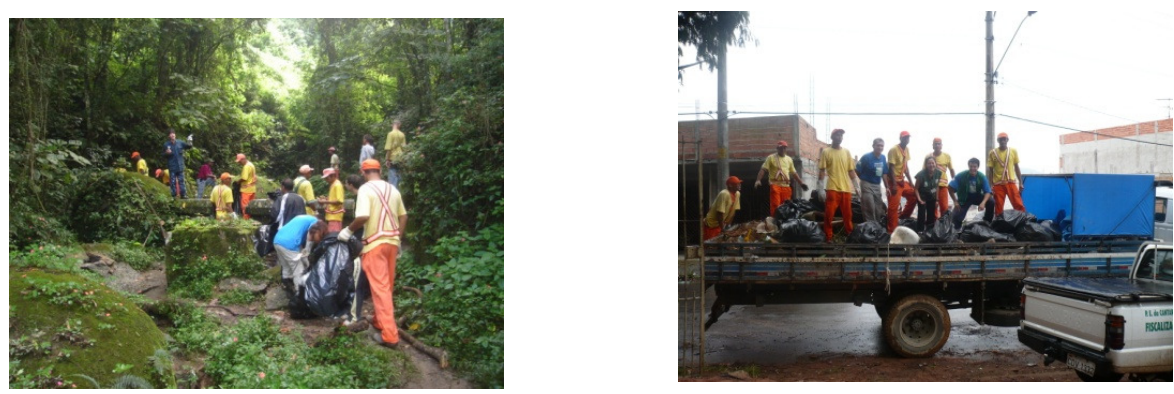

Fig. 1 e 2: Gráfico de mutirões realizados pela Equipe de EA e Uso Público de 2006 a 2010.

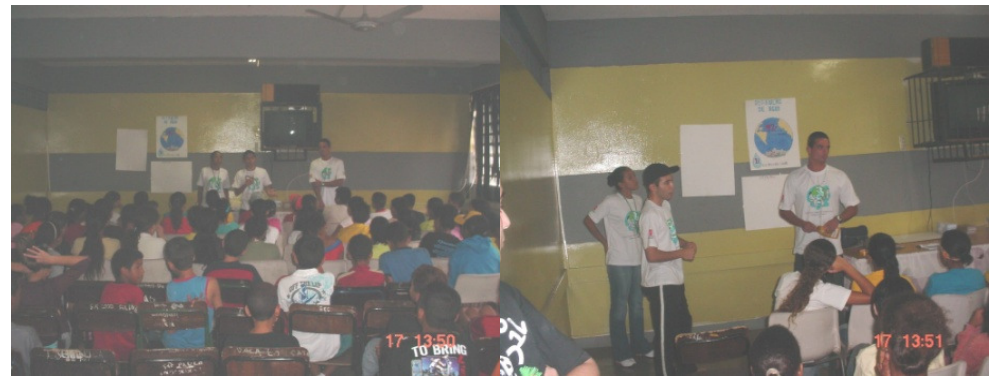

Fig. 3:Palestras realizada pela Equipe de EA e Uso Público de 2006 a 2010. 


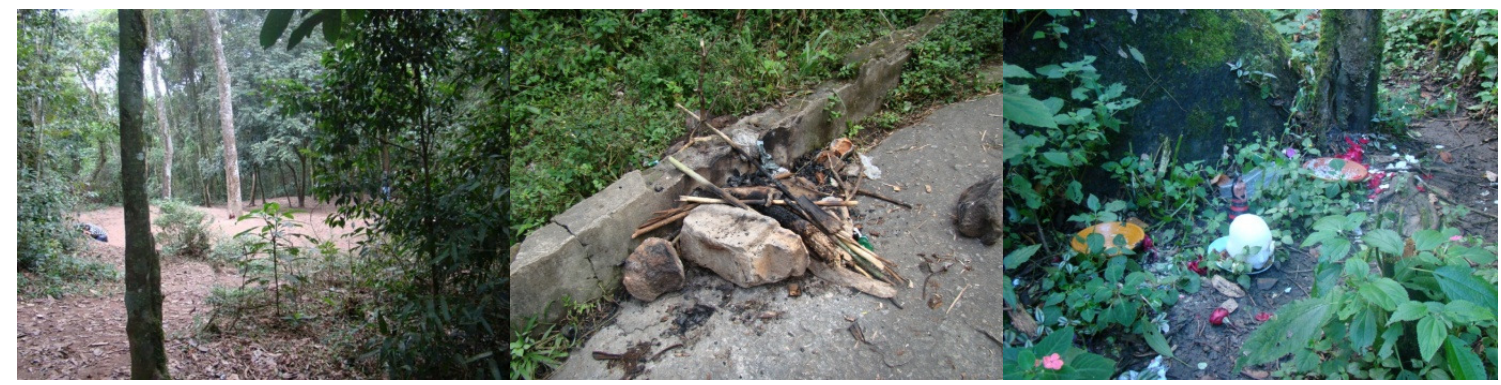

Fig. 4,5 e 6: Região freqüentada por grupos religiosos. Nota-se a quantidade de clareiras na Fig1 e a perca do subosque.

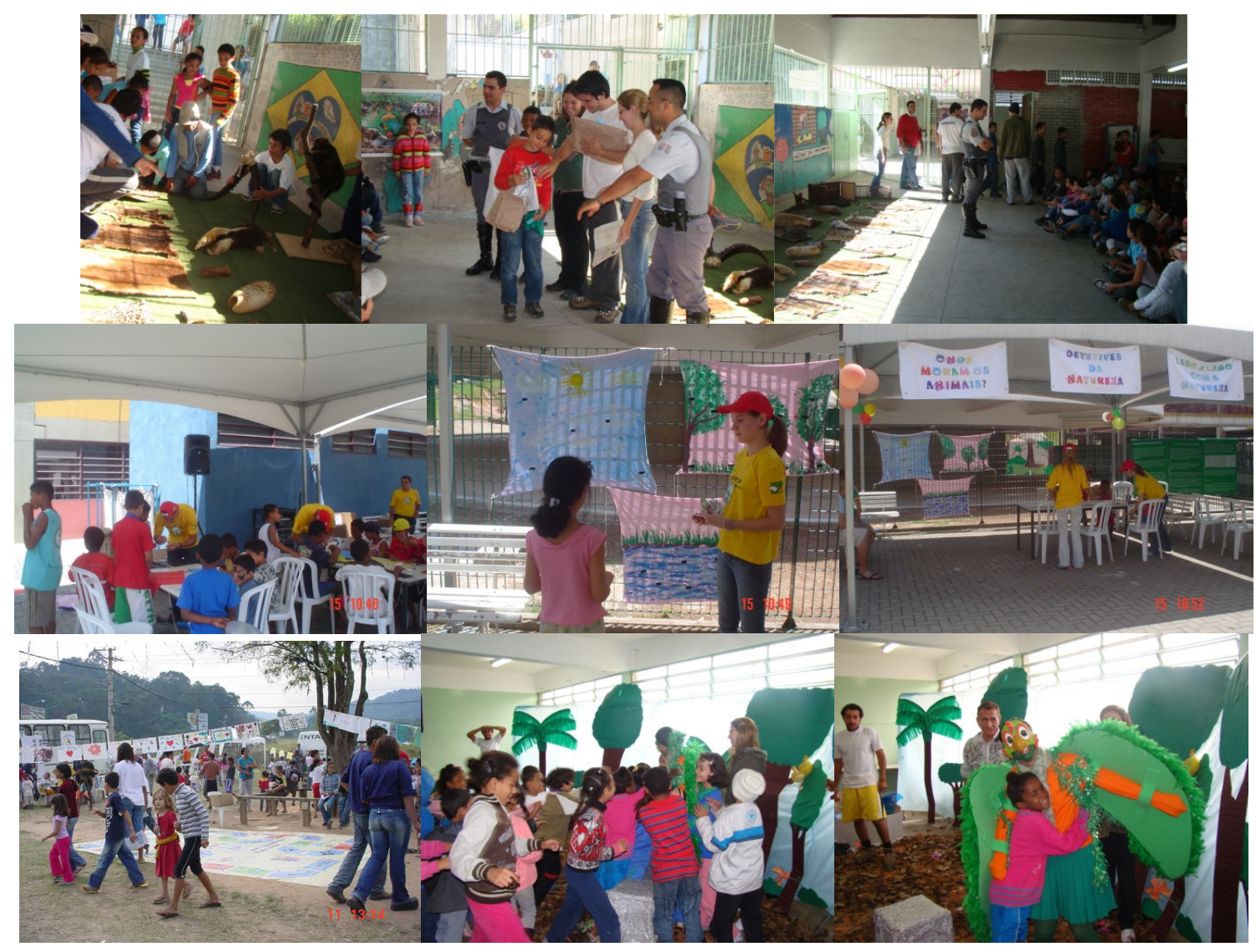

Fig. 7,8,9,10,11,12,13,14 e 15: Atividades culturais realizadas pela Equipe do Projeto de 2006 a 2009.

Até menos de 10 anos atrás as Unidades de Conservação no geral eram criadas sem um plano de viabilidade econômica. Pimentel 2008 apud Pádua, diz que as questões envolvendo problemas fundiários são bastante delicadas e tratadas como um mito em algumas discussões técnicas o que gera um grande desconforto no meio conservacionista e posicionamentos que aparentemente julgam de forma bastante critica as iniciativas de se criar UC's já que quase nenhuma era criada com orçamentos previstos para implementação e regularização fundiária.

Pensando em um Parque que possui seu decreto de criação em 1963, seria inevitável que houvesse conflitos de objetivos de usos da área. Desta forma, para que o Projeto Cuca pudesse alcançar seus objetivos era necessário envolver a comunidade, fortalecer os laços e criar um 
processo educativo capaz de facilitara cooperação múltipla nos processos de decisão, em todos os níveis e etapas (Tratado de Educação Ambiental para Sociedades Sustentáveis), e que este fosse contínuo.

Os atendimentos de escolares dentro do Parque, não sofreram grandes modificações, pois as escolas do entorno continuavam a fazer parte do Programa de Uso Público do Parque, independentemente dos períodos em que Projeto Cuca não atuou. Já em relação às outras ações que necessitavam da equipe para organização e execução, foram descontinuadas em razão das lacunas nos períodos de renovação do contrato e também por não existir um plano de ação para os trabalhos.

A equipe que havia iniciado as atividades acabava por se desligar do Parque em busca de novas oportunidades quando o contrato se findava, e as relações estabelecidas com a comunidade enfraqueciam juntamente com o trabalho de mobilização social. As equipes que se formaram tinham em comum, a necessidade de se realizar o trabalho, um sonho e grandes expectativas, porém esta proposta de trabalho não possuía um plano de execução que levasse em consideração três momentos essenciais que são segundo Cury, 1999 planejar, implementar e avaliar,assim todos os objetivos e atividades eram refeitos, pois uma nova equipe, com um novo olhar assumia os trabalhos.Isto fez com que o Projeto perdesse a força ao longo dos anos.

Além deste novo olhar, muitas vezes a comunidade, que é carente de ouvintes para suas necessidades mais primordiais, enxergou o PEC então como um elo com o Estado, em muitas conversas com líderes comunitários, foi comum ouvir sobre a dificuldade dos moradores em se ter água potável para consumo, moradia ou até mesmo que a associação não provinha de um computador ou materiais para trabalhar. Pimentel 2008apud ORMSBY; KAPLIN, 2005 já diz que no cotidiano os administradores têm que lidar com o manejo da biodiversidade, os interesses das comunidades e a falta de recursos.Este fato atrasava o retorno das ações para o Projeto, o foco se perdia e surgia a necessidade de se readequar e novamente explicaras instituições que ainda participavam qual era o poder de ação da UC, estas novas reuniões demoravam cerca de 2 meses para ocorrer, pois era necessário visitá-los e uni-los novamente.

Além de toda a dificuldade gerada com a comunidade, internamente o projeto enfraquecia, pois tantas mudanças causavam um sentimento de desmotivação na equipe.

Todos estes tropeços descaracterizaram o projeto inicial, dessa maneira o elemento chave de educação ambiental em parque que é (segundo Pimentel, 2008) o de promover a interação da sociedade com o parque através de atividades participativas, acabava não sendo cumprido. $E$ pouco a pouco as instituições que a primeiro momento participavam e interagiam nas atividades do Parque e vice e versa foram se desvinculando.

Em contrapartida, a Equipe repensou sobre as necessidades do Programa de Uso Público e Educação Ambiental internamente, passando então a assumir outras responsabilidades como: a manutenção e manejo das trilhas, a elaboração e manutenção de um viveiro de mudas para atividades de educação ambiental, e a participação da equipe em outros projetos de pesquisa, fortalecendo os Programas de Gestão do Parque, possibilitando a execução de projetos provenientes da Secretaria do Meio Ambiente, e ainda repensar sobre as ações externas propostas pelo Projeto Cuca.

Um dos objetivos principais era criar na comunidade o sentimento de pertencimento, muito bem explicado por Vendrametto 2004, que diz que:

"o laço de pertencimento realmente ocorre quando o cidadão se reconhece como parte integrante de seu meio, participando e interagindo nas atividades diárias e cívicas da sua comunidade. É o sentir-se pessoalmente responsável e proprietário de tudo que constitui seu 
habitat, considerando como sua casa a rua, praça, parques e jardins, vias públicas, as construções e edificações, os monumentos, os meios de transporte as áreas especiais de proteção aos recursos naturais. É um sentimento que ultrapassa o respeito, e busca a conservação, preservação ou manutenção, uso e discussão a respeito do futuro do seu ambiente".

Porém, a abordagem pouco atrativa que muitas vezes estava relacionada apenas com os problemas enfrentados pela UC, com temas e ações pontuais,que foram se descontinuando atrapalharam na criação deste sentimento, visto que a cada novo contrato menos instituições eram ditas como parceiras nos relatórios. Segundo Guimarães 1995, a Educação Ambiental se realizará de forma diferenciada em cada meio para que se adapte às respectivas realidades, trabalhando com seus problemas específicos e soluções próprias em respeito à cultura, aos hábitos, aos aspectos psicológicos, as características biofísicas e socioeconômicas de cada localidade.

Todas estas dificuldades enfrentadas pelas equipes influenciavam diretamente no momento de se estabelecer o que queriam realmente e o que gostariam afinal de Educar? Que tipo de Educação Ambiental seguiriam frente a todas as adversidades? E se questionavam assim como Carvalho, 2004:

\footnotetext{
"Existiria uma educação ambiental para chamar de "sua"? Um tesouro no final do arco-íris para os que alcançarem virtuosamente o coração desta diversidade? (...)

Como fundamentar nossas escolhas? Como conviver com as outras escolhas, as escolhas dos outros? Afinal, como conviver com o Outro, a outridade irredutível da diferença que, particularmente no campo ambiental, se coloca tanto no encontro com os outros humanos quanto no encontro com a natureza enquanto Outro?".
}

Por todos estes entraves a equipe atual, presente no PEC desde 2010, notou a necessidade de criar um plano de ação estruturado para o Projeto, com diretrizes que possam ser executadas independentemente de possíveis mudanças.

\section{CONCLUSÃO}

Mesmo com a diminuição na intensidade dos trabalhos, a equipe nunca parou de atuar na comunidade, atualmente, as atividades que permanecem são: atendimento a escolas do entorno e atividades culturais e as ações externas se restringem ao Mutirão de limpeza da Cuca e a participação nas reuniões da Subprefeitura Freguesia do Ó / Brasilândia responsável pela região. Essas atividades ainda mantêm ativa a participação de algumas instituições.

De acordo com Cohen e Franco, 1984 ONU a descrição de Projeto é "um empreendimento planejado que consiste num conjunto de atividades inter-relacionadas e coordenadas para alcançar objetivos específicos dentro dos limites de um orçamento e de um período de tempo dados", as equipes conviviam com a incerteza de recomeço e continuidade dos trabalhos, e sendo assim tornava-se difícil a tarefa de se traçar um plano de ação, com estratégias bem estruturas e que fossem capazes de serem avaliadas.

Devemos nos lembrar também que assim como constatou Vitiello, 2003 em seu estudo sobre "Educação e Participação em áreas Naturais Protegidas - Caminhos e Obstáculos no Parque Estadual da Cantareira (SP) que os problemas encontrados dentro de uma comunidade carente, como a falta de infra estrutura urbana (ruas pavimentadas, rede de abastecimento de água, luz, 
coleta de lixo) e de equipamentos sociais (escolas, postos de saúde), acabam tornando secundária a discussão sobre a gestão de uma Unidade de Conservação. E a entrada de um Projeto Social na comunidade que tenha como principal objetivo a conservação do meio ambiente, torna-se limitada a multiplicadores que em algum momento de suas vidas já se sensibilizaram e entendem a importância e magnitude do tema.

Para que consigamos driblar estas intempéries diversas discussões e questionamentos ocorreram em relação a estrutura geral do "Projeto" realizado, destacou-se a necessidade de se traçar o devido Plano Estratégico com planejamento, implementação e avaliação, que concorda com o que foi citado anteriormente.

Atualmente um grande passo juntamente a sua reestruturação está sendo dado, pois a empresa CTEEP está desenvolvendo, com auxilio técnico da equipe do projeto, materiais de comunicação, criando assim uma identidade para o Projeto, desta forma acreditamos que ele poderá ser reconhecido apesar das mudanças realizadas com o passar dos anos.

Ainda concluiu-se que esta reformulação é essencial para assegurar a continuidade do processo de Educação Ambiental, a fim de se estabelecer um vinculo permanente entre o Parque e a comunidade, afinal acreditamos que não é possível mantermos a integridade da UC sem que nos lembremos que possuímos em nosso entorno uma quantidade imensa de pessoas que são potenciais multiplicadores de conhecimentos e da conseqüente conservação do PEC.

\section{BIBLIOGRAFIA}

ÁVILA, C.M.Gestão de Projetos Sociais. In: Cury, T.C.H. Elaboração de Projetos Sociais. AAPCS,1999. p. 3656.

CAPRA, F. A teia da vida - Uma nova compreensão cientifica dos sistemas vivos. Editora CultrixLtda, 1996.

IBGE. Instituto Brasileiro de Geografia e Estatística. Censo Populacional. Disponível em: <http://www.ibge.gov.br/home/estatistica/populacao/censo2010/calendario.shtm>. Acesso em 10 jan 2011.

INTITUTO FLORESTAL. Plano de Manejo: Parque Estadual da Cantareira. São Paulo, 1976.

FUNDAÇÃo FLORESTAL. Plano de Manejo: Parque Estadual da Cantareira. São Paulo, 2009.

GUIMARÃES, M. A dimensão ambiental na educação. Campinas: Papirus,1995. 107 p. (Coleção Magistério: Formação e Trabalho Pedagógico) 
PÁDUA, S.M.; TABANEZ, M.F.; SOUZA, M.G. A abordagem participativana educação para a conservação da natureza.In:CULLEN, JR.; L.RUDRAN,R.; VALLADARES-PÁDUA, C.(Org). Métodos de estudo em biologia da conservação e manejo da vida silvestre.Curitiba: Universidade Federal do Paraná; Fundação O Boticário de Proteção à Natureza, 2003.

PIMENTEL, D. S. Os "parques de papel" e o papel social dos Parques. Dissertação (Doutorado) - Escola Superior de Agricultura. Universidade de São Paulo, 2008.

VENDRAMETTO, L.P. Educação Ambiental em Unidades de Conservação: Um estudo de caso na área de proteção ambiental de Sousas e Joaquim Egidio. Dissertação (Mestrado) - Escola Superior de Agricultura “Luiz de Queiroz".Universidade de São Paulo, 2004.

SÃO PAULO (Município). Secretaria Municipal de Coordenação das Subprefeituras. Disponível em: <http://www.prefeitura.sp.gov.br/cidade/secretarias/subprefeituras/> Acesso em: 10 jan 2011.

VITIELLO, M. A. Educação e Participação em Áreas Naturais Protegidas - Caminhos e Obstáculos no Parque Estadual da Cantareira (SP). Dissertação (Mestrado) - Programa de Pós Graduação e Geografia Humana. Universidade de São Paulo, 2003.

PIVELLI, S. R. P. Análise do Potencial Pedagógico de Espaços Não Formais de Ensino para o desenvolvimento da biodiversidade e sua conservação. Dissertação(Mestrado em Educação) Universidade de São Paulo, 2006. 